\title{
La necesidad de una Convención Interamericana para Prevenir, Castigar y Erradicar la violencia contra Niños, Niñas y Adolescentes.
}

\author{
The need of an Inter-american Contention to \\ Prevent, Punish, Erradicate the violence \\ against Children an Teenagers
}

Psic. Clínica. Ana Cecilia Navas *

Pontificia Universidad Católica del Ecuador

Abg. David Cordero Heredia J.S.D.**

Pontificia Universidad Católica del Ecuador

PhD. Efrén Guerrero Salgado***

Pontificia Universidad Católica del Ecuador

Información del artículo

Original - Ruptura, 2020

Artículo recibido/ Received: 01 de junio, 2020

Artículo aceptado/ Accepted: 07 de julio, 2020

* $\quad$ Psicóloga Clínica por la Pontificia Universidad Católica del Ecuador. Licenciatura en educación infantil por la Universidad Técnica Particular de Loja. Especialista en audio logia y rehabilitación vestibular. Técnica en comunicación social por la Universidad Politécnica Salesiana. Especialista en derechos humanos y políticas públicas por la Universidad Andina Simón Bolívar - Sede Ecuador

** Licenciado en Ciencias Jurídicas y Abogado por la Pontificia Universidad Católica del Ecuador; Magíster en Derecho Mención Derecho Constitucional por la Universidad Andina Simón Bolívar sede Ecuador; Master of Laws (LL.M.) por Cornell Law School; Doctor of the Science of Law (J.S.D.), por Cornell Law School.

*** Licenciado en Ciencias Jurídicas y Abogado (PUCE). Máster en Protección de Derechos Humanos por la Universidad de Alcalá. Máster Oficial en Gobierno y Administración Pública por el Instituto Ortega y Gasset, Madrid. Doctor en Gobierno y Administración Pública por la Universidad Complutense de Madrid). Profesor titular en la Facultad de Jurisprudencia de la Pontificia Universidad Católica del Ecuador. Ex decano de la Facultad de Jurisprudencia de la PUCE. 


\section{Citación}

Navas, A., Cordero, D. \& Guerrero, E. (2020). La necesidad de una Convención para Prevenir, Castigar y Erradicar la violencia contra Niños, Niñas y Adolescentes. Revista Ruptura de la Asociación Escuela de Derecho de la PUCE, p (35-48).

DOI: $10.26807 /$ rr.vi02.58

Resumen: Este artículo analiza la necesidad de incrementar la atención de los países de la región en alcanzar la meta de erradicar conjuntamente el maltrato infantil. Por lo tanto, defiende la obligación de introducir un instrumento práctico de protección de derechos, efectivo y capaz de ser enmarcado en las diferentes estructuras de políticas públicas de la región.

Palabras claves: Convención Interamericana, prevención, castigo, violencia, menores.

Abstract: This journal article analyzes the need to strengthen the attention of the countries of the region to achieve the goal of eradicating child violence together. Therefore, it defends the obligation to introduce a practical instrument for the protection of rights, effective and capable of being framed in the different public policy structures of the region.

Keywords: Inter-American Convention, prevention, punishment, violence, minors.

\section{Antecedentes}

Actualmente viven en América Latina casi 195 millones de niños y niñas (UNICEF, 2018). De estos, 6 de cada diez están expuestos a ser víctimas de alguna forma de violencia. Estamos hablando, entonces de un problema que amenaza gravemente la vida, la salud, el proyecto de vida e integridad de un importante sector de la población. 
Este fenómeno ha sido definido por el Derecho Internacional como:

(...) El uso deliberado de la fuerza física o el poder, ya sea en grado de amenaza o efectivo, en contra de una persona, grupo o comunidad que cause o tenga muchas posibilidades de causar lesiones, muerte, daños psicológicos o privaciones, (Informe Mundial violencia y salud de la organización mundial de la salud, 2004, 5) sin embargo, no debemos entender la violencia solamente como actos criminales sino como toda forma de perjuicio o abuso físico o mental, descuido o trato negligente, malos tratos o explotación, incluido el abuso sexual. (Convención para los derechos del niño. Artículo 19, párrafo 1).

La violencia Infantil incluye, entonces los abusos, actos de agresión y la desatención de que son objeto los menores de 18 años; e incluye todos los tipos de maltrato físico o psicológico, abuso sexual, desatención, negligencia y explotación comercial o de otro tipo que causen o puedan causar un daño a la salud, desarrollo o dignidad del niño, o poner en peligro su supervivencia (OMS, 2017).

El número de niños y adolescentes menores de 20 años que fueron víctimas de homicidio llegó a 95.000, lo que convirtió a ese delito en la principal causa prevenible de lesiones, heridas y muerte de menores. A nivel mundial, la región de América Latina y el Caribe tienen la proporción más alta de víctimas de homicidio de menores de 25 años (25.400). El homicidio es la principal causa de muerte de los adolescentes varones en varios países de la órbita latinoamericana, si bien muchos de esos homicidios no son reportados como tales. (UNICEF, 2014).

La violencia contra Niños, Niñas, Adolescentes (en adelante NNA) y mujeres es una de las violaciones de derechos humanos más socialmente extendidas. Esto se debe a que muchas de sus formas se consideran como aceptables o tolerables (Corte IDH. Caso Gutiérrez Hernández y otros vs. Guatemala, Serie C, No. 339, párr. 175). En ese orden de cosas, Latinoamérica y Ecuador sufren una violencia estructural, manifestada en todos los ámbitos: violencia doméstica, en los lugares públicos, en el sistema escolar y en general en muchas 
prácticas culturales o fenómenos globales (ONU, 2011), inclusive en los sistemas disciplinarios (UNICEF, 2006).

Se identifican varios tipos de violencia tales como violencia física, emocional, sexual, emocional, descuido, o matrimonio infantil (UNICEF, 2006). Otros tipos de maltrato tales como el maltrato emocional o psicológico y la negligencia y el trabajo infantil que inclusive se realizan en condiciones violatorias para los derechos humanos ni siquiera se consideran como maltrato o tipo de relaciones anormales en muchos contextos (UNICEF, 2014).

Otros tipos de delitos como los delitos sexuales, el matrimonio infantil, la pornografía infantil y el uso abusivo de la imagen de NNA generalmente no son denunciados, en el ochenta por ciento de casos tiene lugar en el contexto doméstico o dentro de las actividades cotidianas de los NNA, por lo que es ocultado y genera nuevas formas de violencia (UNICEF, 2018). Esto genera un doble estándar social: muchas formas de maltrato en contra de NNA se considerarían entre adultos como agresiones y darían lugar a una intervención de la justicia (ONU, 2011).

Por otra parte, los NNA son las partes más vulnerables en caso de crisis humanitarias (La Vanguardia, 2019), desastres naturales, fenómenos migratorios, situaciones de violencia extrema (BBC, 2019) o en conflictos armados (El Universal, 2019), que en las últimas décadas en la región estas situaciones han estado especialmente extendidas. Estas situaciones han colocado a los NNA en escenarios de especial riesgo y representan un reto para los países de la región en materia de protección (BBC, 2019).

Además, los Niños niñas y adolescentes se hallan más o menos expuestos a la violencia cuando están sujetos a situaciones de desigualdad como pobreza, discriminación por género, discriminación por razones de etnia o procedencia (UNICEF, 2006).

La forma que toma esta violencia además de afectar una parte importante de la población como son los NNA está basada entonces en prácticas discriminatorias que no aseguran la protección de dere- 
chos, tomando en consideración las características específicas de los niños niñas y adolescentes.

Es así como, la violencia a niños niñas y adolescentes es un problema generalizado e invisibilizado que además genera deterioro social $\mathrm{y}$ tiene costos en incremento de problemas generalizados de salud física y emocional generalizado e inclusive conlleva un costo que impide el crecimiento económico de la región (Save the Children,2015). Estos problemas comprenden varios ámbitos surgen de los sujetos y están en el panorama doméstico, pero están ocasionados a nivel sociales y al ser fenómenos globales que afectan a toda la región, requieren de estrategias conjuntas a varios niveles.

Los países de la región ha suscrito convenios tendientes a la protección de los derechos humanos, tales como las declaraciones universales de derechos humanos, la Convención Interamericana de Derechos Humanos, la Declaración Universal para los Derechos del Niño, la Estrategia Mundial para la Salud de la Mujer, el Niño y el Adolescente alineados con los Objetivos para el Desarrollo Sostenible y contienen sus propios elementos internos de protección específica para los derechos de los niños, niñas y adolescentes. Sin embargo, es necesario reforzar la mirada de atención regional para alcanzar la meta de erradicar la violencia infantil de forma conjunta, a través de un instrumento práctico, eficaz y capaz de poder enmarcarse en las diferentes estructuras de políticas públicas de la región.

\section{Justificación}

A pesar de los esfuerzos normativos a nivel local ${ }^{1}$ para erradicar la violencia en contra de niños, niñas y adolescentes, la violencia

1 Entre estos esfuerzos normativos se encuentran: Antigua y Barbuda (Children Care and Protection Bill - 2015), Argentina (Ley 26.061 de 2005 - Ley de Protección Integral de los Derechos de las Niñas, Niños y Adolescentes), Bahamas (Child Protection Act), Barbados (Child Care and Protection Act), Belice (Families and Children Act), Bolivia (Código Niña, Niño y Adolescente), Ecuador (Código de la 
física, psicológica y sexual que sufre este grupo de atención prioritaria en las Américas sigue siendo preocupantes. Al igual que otros problemas persistentes de violaciones de derechos humanos en la región, los órganos regionales y universales de protección de derechos humanos, trabajando junto a los estados y organizaciones de la sociedad civil, buscan la coordinación de esfuerzos a nivel interestatal con el fin convertirse en foros sobre desarrollo de buenas prácticas y en órganos de justicia subsidiarios que coadyuven a los esfuerzos locales de protección.

La Convención Americana de Derechos Humanos, de 1969, creó la Corte Interamericana de Derechos Humanos, institución que junto con la Comisión Interamericana de Derechos Humanos (creada mediante en 1959) han asistido a los estados miembros de la Organización de Estados Americanos para que cumplan a cabalidad sus obligaciones internacionales en el marco de los instrumentos que componen el Sistema Interamericano de Protección de los Derechos Humanos (en adelante SIDH). ${ }^{2}$

Niñez y Adolescencia), Colombia (Ley 1098 de 2006 - Código de la Infancia y la Adolescencia), Chile (Ley 20066 de 2005 - Ley de Violencia Intrafamiliar), El Salvador (Ley de Protección Integral de la Niñez y Adolescencia), Granada (Domestic Violence Act), Guatemala (Ley de Protección de la Infancia y la Adolescencia), Honduras (Código de la Niñez y de la Adolescencia), Jamaica (Child Care and Protection Act), México (Decreto por el cual se expide la Ley General de los Derechos de Niñas, Niños y Adolescentes, y se reforman diversas disposiciones de la Ley General de Prestación de Servicios para la Atención, Cuidado y Desarrollo Integral Infantil), República Dominicana (Código para la protección de los derechos de los Niños, Niñas y Adolescentes), Panamá (Código de Familia), Perú (Código de la Infancia y la Adolescencia), Uruguay (Código de la Infancia y la Adolescencia), Venezuela (Ley Orgánica para la Protección de Niños, Niñas y Adolescentes). Los instrumentos que componen el SIDH son: Declaración Americana de los Derechos y Deberes del Hombre (1948), Convención Americana sobre Derechos Humanos (1969), Convención Interamericana para Prevenir y Sancionar la Tortura (1985), "Protocolo de San Salvador": Protocolo Adicional a la Convención Americana en Materia de Derechos Económicos, Sociales y Culturales (1988), Protocolo a la Convención Americana sobre Derechos Humanos relativo a la Abo- 
El SIDH fue concebido como un sistema auxiliar a las jurisdicciones nacionales en la protección de derechos humanos. Su sistema de peticiones individuales se activa únicamente luego de que se hayan agotado los recursos de jurisdicción interna (Corte IDH. Caso Castañeda Gutman vs. Estados Unidos Mexicanos. Serie C No. 184, párr. 34) y constituye la última línea de defensa para las personas y pueblos que no han encontrado respeto y garantía de sus derechos humanos dentro de sus estados.

Además, sus funciones consultivas (CIDH. Opinión Consultiva OC-1/82. Serie A No. 1), de seguimiento del cumplimiento de tratados, de informes temáticos y de país, de adopción de medidas cautelares y provisionales, de visitas in loco y eventos de promoción del SIDH, han ayudado por varias décadas a los estados americanos a implementar el Derecho Interamericano dentro de sus jurisdicciones; y, por tanto, mejorar la protección de los derechos humanos de las personas y pueblos, así como prevenir el ser encontrados internacionalmente responsables por la violación de los instrumentos internacionales que componen la SIDH.

En varios temas, el SIDH ha sido pionero en la inclusión y desarrollo de instituciones jurídicas dentro de los estados: derechos de los pueblos indígenas, ${ }^{3}$ prohibición de la censura previa y res-

lición de la Pena de Muerte (1990), "Convención de Belém do Pará”: Convención Interamericana para Prevenir, Sancionar y Erradicar la Violencia Contra la Mujer (1994), Convención Interamericana sobre Desaparición Forzada de Personas (1994), Convención Interamericana para la Eliminación de todas las Formas de Discriminación contra las Personas con Discapacidad (1999), Convención Interamericana contra el Racismo, la Discriminación Racial y Formas Conexas de Intolerancia (2013), Convención Interamericana contra toda Forma de Discriminación e Intolerancia (2013), Convención Interamericana sobre la Protección de los Derechos Humanos de las Personas Mayores (2015) y Declaración Americana sobre los derechos de los pueblos indígenas (2016).

3 Corte IDH. Caso de la Comunidad Mayagna (Sumo) Awas Tingni Vs. Nicaragua. Fondo, Reparaciones y Costas. Sentencia de 31 de agosto de 2001. Serie C No. 79. Corte IDH. Caso Comunidad Indígena Yakye Axa Vs. Paraguay. Fondo, Reparacio- 


\section{ponsabilidad ulterior ${ }^{4}$ excepcionalidad de la prisión preventiva, ${ }^{5}$}

nes y Costas. Sentencia de 17 de junio de 2005. Serie C No. 125. Corte IDH. Caso del Pueblo Saramaka Vs. Surinam. Interpretación de la Sentencia de Excepciones Preliminares, Fondo, Reparaciones y Costas. Sentencia de 12 de agosto de 2008. Serie C No. 185. Corte IDH. Caso Pueblo Indígena Kichwa de Sarayaku Vs. Ecuador. Fondo y Reparaciones. Sentencia de 27 de junio de 2012. Serie C No. 245. CIDH. Informe sobre Mujeres Indígenas y sus derechos humanos en las Américas (2017). CIDH. Informe sobre Pueblos indígenas, comunidades afrodescendientes, industrias extractivas (2016). CIDH. Informe sobre Pueblos indígenas en aislamiento voluntario y contacto inicial en las Américas (2013). CIDH. Informe sobre Derechos de los Pueblos Indígenas y Tribales sobre sus Tierras Ancestrales y Recursos Naturales (2009). CIDH. Informe sobre Comunidades Cautivas: Situación del pueblo indígena guaraní y formas contemporáneas de esclavitud en el Chaco de Bolivia (2009). CIDH. Informe sobre La Situación de los Derechos Humanos de los Indígenas en las Américas (2000)

4 Corte IDH. Caso "La Última Tentación de Cristo" (Olmedo Bustos y otros) Vs. Chile. Fondo, Reparaciones y Costas. Sentencia de 5 de febrero de 2001. Serie C No. 73. Corte IDH. Caso Herrera Ulloa Vs. Costa Rica. Excepciones Preliminares, Fondo, Reparaciones y Costas. Sentencia de 2 de julio de 2004. Serie C No. 107. Corte IDH. Caso Kimel Vs. Argentina. Fondo, Reparaciones y Costas. Sentencia de 2 de mayo de 2008. Serie C No. 177. Corte IDH. Caso Fontevecchia y D`Amico Vs. Argentina. Fondo, Reparaciones y Costas. Sentencia de 29 de noviembre de 2011. Serie C No. 238. Relatoría Especial sobre Libertad de Expresión de la CIDH. Informe sobre Marco Jurídico Interamericano sobre Libertad de Expresión (2009). Relatoría Especial sobre Libertad de Expresión de la CIDH. Informe sobre Informe sobre las Leyes de Desacato y Difamación Criminal (2004).

Corte IDH. Caso Suárez Rosero Vs. Ecuador. Fondo. Sentencia de 12 de noviembre de 1997. Serie C No. 35, párr. 77, y Caso Bayarri Vs. Argentina. Excepción Preliminar, Fondo, Reparaciones y Costas. Sentencia de 30 de octubre de 2008. Serie C No, 187. Corte IDH. Caso Tibi Vs. Ecuador. Excepciones Preliminares, Fondo, Reparaciones y Costas. Sentencia de 7 de septiembre de 2004. Serie C No. 114. Corte IDH. Caso Mujeres Víctimas de Tortura Sexual en Atenco Vs. México. Excepción Preliminar, Fondo, Reparaciones y Costas. Sentencia de 28 de noviembre de 2018. Serie C No. 371. CIDH. Informe sobre el uso de la prisión preventiva en las Américas (2013). CIDH. Informe sobre los Derechos Humanos de las Personas Privadas de Libertad en las Américas (2011). 
tipificación e investigación de la desaparición forzada de personas, ${ }^{6}$ derecho a la vida digna, ${ }^{7}$ protección a niños, niñas y adolescentes en situación de movilidad, ${ }^{8}$ derecho a la identidad de niños, niñas

6 Corte IDH. Caso Velásquez Rodríguez Vs. Honduras. Fondo. Sentencia de 29 de julio de 1988. Serie C No. 4. Corte IDH. Caso Castillo Páez Vs. Perú. Fondo. Sentencia de 3 de noviembre de 1997. Serie C No. 34. Corte IDH. Caso Chitay Nech y otros Vs. Guatemala. Excepciones Preliminares, Fondo, Reparaciones y Costas. Sentencia de 25 de mayo de 2010. Serie C No. 212. Corte IDH. Caso Alvarado Espinoza y otros Vs. México. Fondo, Reparaciones y Costas. Sentencia de 28 de noviembre de 2018. Serie C No. 370. CIDH. Informe sobre Mujeres indígenas desaparecidas y asesinadas en Columbia Británica, Canadá (2015).

7 Corte IDH. Caso de los "Niños de la Calle” (Villagrán Morales y otros) Vs. Guatemala. Fondo. Sentencia de 19 de noviembre de 1999. Serie C No. 63. Corte IDH. Caso Comunidad Indígena Yakye Axa Vs. Paraguay. Fondo Reparaciones y Costas. Sentencia 17 de junio de 2005. Serie C No. 125. Corte IDH. Caso Zambrano Vélez y otros Vs. Ecuador. Fondo, Reparaciones y Costas. Sentencia de 4 de julio de 2007. Serie C No. 166. Corte IDH. Caso Gonzales Lluy y otros Vs. Ecuador. Excepciones Preliminares, Fondo, Reparaciones y Costas. Sentencia de 01 de septiembre de 2015. Serie C No. 298.

8 Corte IDH. Caso de las niñas Yean y Bosico Vs. República Dominicana. Sentencia de 8 de septiembre de 2005. Serie C No. 130. Corte IDH. Caso Yarce y otras Vs. Colombia. Excepción Preliminar, Fondo, Reparaciones y Costas. Sentencia de 22 de noviembre de 2016. Serie C No. 325. Corte IDH. Caso de personas dominicanas y haitianas expulsadas Vs. República Dominicana. Excepciones Preliminares, Fondo, Reparaciones y Costas. Sentencia de 28 de agosto de 2014. Serie C No. 282. Corte IDH. Derechos y garantías de niñas y niños en el contexto de la migración y/o en necesidad de protección internacional. Opinión Consultiva OC-21/14 de 19 de agosto de 2014. Serie A No. 21. CIDH. Informe sobre Movilidad Humana, Estándares Interamericanos (2016). 


\section{y adolescentes, ${ }^{9}$ no discriminación de personas LGBTI, ${ }^{10}$ violencia contra la mujer, ${ }^{11}$ entre otros.}

9 Corte IDH. Caso Gelman Vs. Uruguay. Fondo y Reparaciones. Sentencia de 24 de febrero de 2011. Serie C No. 221. Corte IDH. Caso Ramírez Escobar y otros Vs. Guatemala. Fondo, Reparaciones y Costas. Sentencia de 9 de marzo de 2018. Serie C No. 351. Corte IDH. Condición jurídica y derechos humanos del niño. Opinión Consultiva OC-17/02 de 28 de agosto de 2002. Serie A No. 17.

10 Corte IDH. Caso Atala Riffo y niñas Vs. Chile. Solicitud de Interpretación de la Sentencia de Fondo, Reparaciones y Costas. Sentencia de 21 de noviembre de 2012. Serie C No. 254. Corte IDH. Caso Flor Freire Vs. Ecuador. Excepción Preliminar, Fondo, Reparaciones y Costas. Sentencia de 31 de agosto de 2016. Serie C No. 315. Corte IDH. Caso Duque Vs. Colombia. Excepciones Preliminares, Fondo, Reparaciones y Costas. Sentencia de 26 de febrero de 2016. Serie C No. 310. Corte IDH. Identidad de género, e igualdad y no discriminación a parejas del mismo sexo. Obligaciones estatales en relación con el cambio de nombre, la identidad de género, y los derechos derivados de un vínculo entre parejas del mismo sexo (interpretación y alcance de los artículos 1.1, 3, 7, 11.2, 13, 17, 18 y 24, en relación con el artículo 1 de la Convención Americana sobre Derechos Humanos). Opinión Consultiva OC-24/17 de 24 de noviembre de 2017. Serie A No. 24. Relatoría Especial sobre Libertad de Expresión de la CIDH. Informe sobre Discurso de odio y la incitación a la violencia contra las personas lesbianas, gays, bisexuales, trans e intersex en América (2015). CIDH. Informe sobre Violencia contra personas LGBTI (2015).

11 Corte IDH. Caso Fernández Ortega y otros Vs. México. Excepción Preliminar, Fondo, Reparaciones y Costas. Sentencia de 30 de agosto de 2010. Serie C No. 215. Corte IDH. Caso Mujeres Víctimas de Tortura Sexual en Atenco Vs. México. Excepción Preliminar, Fondo, Reparaciones y Costas. Sentencia de 28 de noviembre de 2018. Serie C No. 371. Corte IDH. Caso González y otras ("Campo Algodonero") Vs. México. Excepción Preliminar, Fondo, Reparaciones y Costas. Sentencia de 16 de noviembre de 2009. Serie C No. 205. Relatoría Especial sobre Libertad de Expresión de la CIDH. Informe sobre Acceso a la información pública en materia de violencia y discriminación contra las mujeres: avances y desafíos pendientes en las Américas (2018). CIDH. Informe No. 54/01- Fondo, Caso 12.051, Maria da Penha Maia Fernandes (Brasil), 2000. CIDH. Informe No. 51/13, Caso 12.551, Paloma Ángelica Escobar Ledezma y otros, 2013. 
Organizaciones como CEJIL han estudiado los efectos favorables que han tenido las actuaciones del SIDH (CEJIL, 2007), las decisiones de sus órganos han logrado en muchos casos movilizar sectores sociales y funcionarios públicos para la implementación de decisiones que no siempre van dirigidas en contra de los estados que deciden adoptar nuevos estándares. Cabe añadir que la doctrina del control de convencionalidad (CIDH, Cuadernillo No. 7) ha permitido a jueces, juezas, tribunales y cortes nacionales tener un rol más activo en la implementación de los estándares internacionales de derechos humanos.

\section{Conclusiones}

En conclusión, el SIDH es una plataforma valiosa, no solo porque permita a las personas y pueblos que sufren violaciones de derechos humanos contar con una instancia adicional a la cual acudir en búsqueda de una reparación integral a sus derechos, sino que es además un foro en el que se adelantan reformas constitucionales, legales y de políticas públicas en favor de las personas y los pueblos de las Américas.

La violencia en contra de niños, niñas y adolescentes, como problema que requiere un tratamiento regional, encontrará en el SIDH el espacio para su desarrollo técnico acompañado de la supervisión de la CIDH y la Corte IDH (CIDH, 2009). La importancia y especificidad del tema ameritan a que esta conversación regional se inicie con una Convención Interamericana para Prevenir, Sancionar y Erradicar la Violencia en Contra de Niños, Niñas y Adolescentes, que sirva como mecanismo que complete el corpus iure interamericano (Corte IDH. Caso V.R.P., V.P.C. y otros vs. Nicaragua. Serie C. No. 350, párr. 155) y dote al SIDH y a los estados que tengan el concepto de "bloque de constitucionalidad" una herramienta de aplicación eficaz de los principios que ya han sido analizados por la Corte IDH en su jurisprudencia. 


\section{Referencias Bibliográficas}

Centro por la Justicia y el Derecho Internacional (CEJIL). (2007). Implementación de las decisiones del Sistema Interamericano de Derechos Humanos. Jurisprudencia, normativa y experiencias nacionales. Buenos Aires - Argentina

Comité de los Derechos del Niño. (18 de abril de 2011). Observación General No. 13. Derecho del niño a no ser víctima de ninguna forma de violencia.

Comisión Interamericana de Derechos Humanos. (24 de septiembre de 1982). Opinión Consultiva OC-1/82. Serie A No. 1.

Comisión Interamericana de Derechos Humanos (2009). Informe Sobre el Castigo Corporal y los Derechos Humanos de las Niñas, Niños y Adolescentes.

Corte Interamericana de Derechos Humanos. (s/f). Cuadernillo de Jurisprudencia de la Corte Interamericana de Derechos Humanos No7: Control de Convencionalidad.

Fondo de las Naciones Unidas para la Infancia (UNICEF). (2006). Cuarenta por ciento de los adultos considera los castigos físicos como necesarios para la disciplina en la mayoría de países de Latinoamérica. Tercer estudio de maltrato infantil.

Fondo de las Naciones Unidas para la Infancia (UNICEF). (2014). Ocultos a Plena luz, un análisis estadístico de la violencia en contra de niños, niñas y adolescentes en 123 países. Recuperado de https://files.unicef.org/publications/ files/Hidden_in_plain_sight_statistical_analysis_E_N_3_Sept2014.pd

Fondo de las Naciones Unidas para la Infancia (UNICEF). (2018). Niños y Niñas en América Latina Panorama 2018. Recuperado de https://www.unicef.org/lac/informes/ninos-y-ninas-en-america-latina-y-el-caribe

Fondo de las Naciones Unidas para la Infancia, UNICEF Uruguay \& Ministerio de Salud Pública de la República Oriental del Uruguay (2018). Protocolo para el abordaje de situaciones de violencia sexual hacia niñas, niños y adolescents en el marco del Sistema Nacional Integrado de Salud. UNICEF 
Uruguay. Recuperado de https://www.bibliotecaunicef.uy/doc_num. php?explnum_id=193

EL UNIVERSAL. (27 de abril de 2019). Los niños víctimas invisibles de la Guerra contra el narco y el crimen organizado en México. Recuperado de https:// www.eluniversal.com.mx/nacion/los-ninos-las-victimas-invisibles-de-laguerra-contra-el-narco-y-el-crimen-organizado-en

Organización Mundial de la Salud. (2004). Informe Mundial violencia y salud.

Organización de las Naciones Unidas. (2011) Estudio del Secretario General de Naciones Unidas, sobre violencia en niñas, niños y adolescentes.

Organización Panamericana de la Salud \& Organización Mundial de la Salud. (2017) Maltrato Infantil. Recuperado de https://www.paho.org/hq/index. php?option $=$ com_content $\&$ view $=$ article $\&$ id $=11122$ :violence-against - children\&Itemid $=41533 \& l a n g=e s$

Save the Children. Oficina Regional para América Latina y el Caribe. (2015). El impacto de la violencia en la vida de los niños, niñas y Adolescentes en América Latina y el Caribe. Recuperado de https://www.refworld.org.es/pdfid/5af1cbb14.pdf

Rojas, A. (26 de abril de 2019). Los niños, las víctimas invisibles de la guerra contra el narco y el crimen organizado en México. BBC NEWS MUNDO. Recuperado de https://www.bbc.com/mundo/noticias-america-latina-48060807

Palomino, M. (29 de abril 2019). Al menos 400.000 niños y niñas ha dejado Venezuela por crisis humanitaria. La Vanguardia. Recuperado de https://www. lavanguardia.com/vida/20190429/461950896303/al-menos-400000-ninos-y-ninas-han-dejado-venezuela-por-crisis-humanitaria.html

Montenegro, C. (20 de junio de 2019). Crisis en Venezuela: la difícil vida de los niños y adolescentes venezolanos en el norte de Brasil. BBC Brasil. Recuperado de: https://www.bbc.com/mundo/noticias-america-latina-48704762. 


\section{Jurisprudencia internacional}

Corte Interamericana de Derechos Humanos. Caso Castañeda Gutman Vs. Estados Unidos Mexicanos. Excepciones Preliminares, Fondo, Reparaciones y Costas. Sentencia de 6 de agosto de 2008. Serie C No. 184.

Corte Interamericana de Derechos Humanos. Caso Gutiérrez Hernández y otros Vs. Guatemala. Excepciones Preliminares, Fondo, Reparaciones y Costas. Sentencia de 24 de agosto de 2017. Serie C No. 339.

Corte Interamericana de Derechos Humanos. Caso V.R.P., V.P.C. y otros Vs. Nicaragua. Excepciones Preliminares, Fondo, Reparaciones y Costas. Sentencia de 8 de marzo de 2018. Serie C No. 350. 